\title{
KAJIAN PREFERENSI PENGGUNA MODA TRANSPORTASI KERETA API LRT JAKARTA MENUJU STASIUN LRT VELODROME
}

\author{
Khansa Ramadianti ${ }^{1, *)}$, Nunung Widyaningsih ${ }^{1)}$ \\ ${ }^{1)}$ Jurusan Teknik Sipil Universitas Mercu Buana \\ Jl. Raya Meruya Selatan, Kembangan, DKI Jakarta, 11650 \\ ${ }^{*}$ Email : khansaramadianti@gmail.com
}

\begin{abstract}
The Government of Jakarta is trying to reduce the traffic volume by launching many new rail-based public transportation modes in this Jakarta Capital Region, one of them is Jakarta LRT. There are so many special things at the LRT Velodrome Station, for example the strategic location of Velodrome, the Jakarta International Velodrome stadium, integrated with Transjakarta transportation mode, etc. Even though the Jakarta LRT is the new transportation mode, but the Jakarta LRT only used by few people, because the route is still too short only 5,6 km (Pengangsaan Dua to Velodrome). So, this research discuss about the preference of passengers in using Jakarta LRT as the option for their daily transportation. The analysis of data obtained in this research by using the "Importance Performance Analysis" method, and analyzed the validity and reliability by using SPSS 24 program. The results of people's preferences by using Jakarta LRT in this research are located in quadrant II that have a good performance on passengers satisfaction, so the performance must be maintained. And the items that needs to be improved for the efficiency and effectiveness are located in quadrant I that requires the high priority on its performance.
\end{abstract}

Kata kunci : LRT Jakarta, preferensi, importance performance analysis, jalur kereta

\section{PENDAHULUAN}

Transportasi umum merupakan salah satu aspek yang sangat penting dalam perkembangan suatu wilayah seperti di Ibukota Jakarta. Sektor transportasi umum di Ibukota saat ini sedang dikembangkan oleh Pemerintah DKI Jakarta tujuannya untuk mengurangi tingkat kemacetan akibat kendaraan pribadi serta polusi udara. Salah satu moda transportasi umum yang popular saat ini di wilayah Ibukota adalah Kereta Api. Peningkatan pembangunan moda transportasi kereta api memiliki keunggulan seperti mempunyai perlintasan sendiri sehingga tidak terganggu lalu lintas lainnya, serta dapat mengangkut penumpang dengan jumlah yang tinggi.

Transportasi adalah perpindahan manusia atau barang dari satu tempat ke tempat lainnya dengan menggunakan sebuah kendaraan yang digerakkan oleh manusia atau mesin. Menurut Morlok (1984), transportasi adalah kegiatan untuk menggerakan atau memindahkan orang dan / atau barang dari satu tempat ke tempat lain 
dengan menggunakan system tertentu untuk tujuan tertentu. Menurut Tamin (1997) beberapa tujuan transportasi yaitu:

1. Mewujudkan lalu lintas dan angkutan jalan yang selamat, aman, cepat, lancar, tertib dan teratur.

2. Memadukan dengan transportasi lainnya dalam suatu kesatuan sistem transportasi nasional.

3. Menjangkau seluruh pedalaman wilayah daratan guna menunjang pemerataan perturnbuhan dan stabilitas serta sebagai pendorong dalam pembangunan nasional.

LRT (Light Rail Transit) Jakarta atau Lintas Rel Terpadu atau Kereta Api Ringan merupakan salah satu moda transportasi kereta api yang populer di wilayah Ibukota. LRT Jakarta Selain karena mempunyai lintasan sendiri yang artinya tidak terganggu oleh lalu lintas lainnya, juga LRT Jakarta merupakan kereta api ringan yang mempunyai daya angkut dua kali lebih besar dari bus terpadu. Berdasarkan Peraturan Gubernur Provinsi Daerah Khusus Ibukota Jakarta Nomor 103 Tahun 2007 Tentang Pola Transportasi Makro, Light Rail Transit yang selanjutnya disingkat LRT adalah angkutan umum massal cepat dengan menggunakan kereta ringan. Kereta api ringan dikenal juga sebagai LRT (Light Rail Transit) adalah salah satu sistem kereta api penumpang yang beroperasi dikawasan perkotaan yang konstruksinya ringan dan bisa dioperasikan berjalan bersama lalu lintas kendaraan lain atau dalam lintasan yang khusus diperuntukkan bagi kereta api ringan.

LRT Jakarta memiliki keunggulan yaitu pada stasiun Velodrome yang memiliki daya tarik tersendiri sebagai penunjang minat pengguna LRT Jakarta, yaitu stasiun Velodrome merupakan stasiun yang strategis dikarenakan pemberhentiannya tepat di salah satu stadion besar di Jakarta bernama Jakarta International Velodrome serta terdapat pusat perbelanjaan bernama Arion Mall, juga stasiun Velodrome ini terintegrasi dengan halte transjakarta yang mampu menghubungkan moda transportasi lainnya seperti KRL dan MRT Jakarta.

Walaupun LRT Jakarta merupakan moda transportasi baru, namun rute LRT Jakarta yang masih cenderung pendek (Pegangsaan Dua sampai Velodrome) sehingga hanya masyarakat tertentu saja yang menggunakan LRT Jakarta sebagai transportasi sehari-hari sehingga masih perlu adanya beberapa preferensi tentang masyarakat yang sudah mencoba dan menggunakan moda transportasi LRT Jakarta dalam kesehariannya.

Adapun dalam penelitian terdahulu yang telah dilakukan oleh Widyaningsih (2017) menyatakan bahwa KAI Commuter Line rute Tanah Abang - Serpong termasuk dalam kategori yang mempertahankan kinerjanya (Kuadran B), namun perlu adanya peningkatan pada faktor layanan yang belum sesuai dengan harapan penumpang yaitu item-item yang berada pada kuadran A. Maka, 
dalam penelitian ini akan membahas mengenai hubungan kinerja LRT Jakarta dengan kepentingan penumpang sebagai preferensi dalam menggunakan LRT Jakarta sebagai moda transportasi dalam kesehariannya.

\section{METODE PENELITIAN}

Penelitian ini dilakukan di sepanjang lokasi LRT Jakarta (Stasiun Pegangsaan Dua - Stasiun Velodrome). Dan penelitian dilaksanakan di bulan Juni 2020 . Untuk menentukan jumlah sampel/responden, peneliti menggunakan metode sampling dengan memperhatikan hal-hal berikut:

1. Responden merupakan penumpang atau pengguna LRT Jakarta dari stasiun Pegangsaan Dua, Boulevard Utara, Boulevard Selatan, Pulomas, dan Equestrian.

2. Peneliti menggunakan rumus Slovin untuk menentukan jumlah responden.

Berikut merupakan rumus Slovin dalam Umar (2011) yang digunakan untuk menentukan jumlah responden:

Keterangan:

$$
n=\frac{N}{\left(1+N e^{2}\right)} \#(1)
$$

$\mathrm{n}=$ jumlah sampel/responden

$\mathrm{N}=$ jumlah populasi

$\mathrm{E}=$ persen kelonggaran ketidaktelitian, $10 \%$

Berdasarkan data yang diperoleh dari PT LRT Jakarta, jumlah penumpang rata-rata perhari adalah 7000 jiwa, sehingga didapat:

$$
n=\frac{7000}{\left(1+7000(0,1)^{2}\right)}
$$

Didapat $\mathrm{n}=98$ jiwa, maka sampel yang dibutuhkan dibulatkan menjadi 100 sampel/responden.

\section{Teknik Analisis Data}

Sebelum memasuki teknik analisis data, hasil dari pengambilan data melalui kuisioner dilakukan uji validitas dan uji reliabilitas terlebih dahulu, sehingga secara statistik hasil pengujiannya layak digunakan. Uji validitas dan uji reliabilitas menggunakan program SPSS versi 24. Uji validitas digunakan untuk mengetahui valid atau tidaknya suatu kuisioner. Sedangkan uji reliabititas digunakan untuk mengetahui suatu kuisioner reliabel/konsisten.

Teknik analisis data pada penelitian ini menggunakan metode Importance Performance Analysis untuk mengetahui bagaimana kepentingan masyarakat (importance) terhadap kinerja (performance) LRT Jakarta dan penilaian pada stasiun Velodrome. IPA menggabungkan dua faktor tingkat kepentingan masyarakat dan kinerja perusahaan dalam grafik dua dimensi yang memudahkan penjelasan data. Dalam penelitian ini terdapat dua variable, yaitu variable $\mathrm{x}$ dan variable $y$, dimana:

1. Variable $\mathrm{x}$ merupakan tingkat kualitas berdasarkan kinerja PT LRT Jakarta.

2. Variabel y merupakan tingkat kepentingan masyarakat pengguna LRT Jakarta rute Pegangsaan Dua - Velodrome serta penilaian 
kepuasan terhadap stasiun

Velodrome.

Rumus yang digunakan dalam Importance Performance Analysis:

$$
T K i=\frac{x i}{y i} \times 100 \% \#(2)
$$

Dimana:

$\mathrm{TKi}=$ Tingkat Kesesuaian

Responden

$\mathrm{Xi}=$ Bobot Penilaian Kinerja PT LRT jakata

Yi = Bobot Penilaian Kepentingan dan Kepuasan Masyarakat

Sumbu mendarat (x) diisi nilai kinerja, sedangkan sumbu tegak (y) diisi nilai kepentingan dan kepuasan masyarakat.

$$
\begin{aligned}
X i & =\frac{\sum x i}{n i} \#(3) \\
Y i & =\frac{\sum y i}{n i} \#(4)
\end{aligned}
$$

Dimana:

$\mathrm{X}=$ Nilai Rata-Rata Tingkat Kinerja

$\mathrm{Y}=$ Nilai Rata-Rata Tingkat

Kepentingan dan Kepuasan

$\mathrm{N}=$ Jumlah Responden

\section{HASIL DAN PEMBAHASAN}

Hasil dari analisis data kuisioner sebanyak 100 responden yang menggunakan moda transportasi LRT Jakarta menuju stasiun LRT Velodrome diolah dengan menggunakan metode Importance Performance Analysis dan didapatkan hasil Tabel 1 berikut:

\begin{tabular}{|c|c|c|c|c|c|}
\hline \multirow{2}{*}{ No } & \multirow{2}{*}{ Faktor Pelayanan } & \multicolumn{2}{|c|}{ Penilaian } & \multicolumn{2}{|c|}{ Rata-Rata } \\
\hline & & Kinerja & Kepuasan & $\mathrm{X}$ & Y \\
\hline & Tangibles & & & & \\
\hline 1 & Kondisi Kereta api LRT Jakarta & 429 & 438 & 4,29 & 4,38 \\
\hline 2 & $\begin{array}{l}\text { Kelengkapan fasilitas di dalam gerbong } \\
\text { kereta api LRT Jakarta (AC, kursi } \\
\text { penumpang, rak bagasi) }\end{array}$ & 420 & 412 & 4,2 & 4,12 \\
\hline \multirow[t]{3}{*}{3} & $\begin{array}{l}\text { Kelengkapan fasilitas keamanan di dalam } \\
\text { gerbong kereta }\end{array}$ & 407 & 411 & 4,07 & 4,11 \\
\hline & $\begin{array}{ll}\text { Rata-rata Tangibles } \\
\end{array}$ & & & 4,19 & 4,20 \\
\hline & Reliability & & & & \\
\hline 4 & $\begin{array}{l}\text { Ketepatan waktu datang dan berangkatnya } \\
\text { kereta api LRT Jakarta (Headway } 5 \text { - } 10 \\
\text { menit) }\end{array}$ & 411 & 406 & 4,11 & 4,06 \\
\hline \multirow[t]{3}{*}{5} & $\begin{array}{l}\text { Ketepatan waktu perjalanan kereta api LRT } \\
\text { Jakarta }\end{array}$ & 423 & 413 & 4,23 & 4,13 \\
\hline & Rata-rata Reliability & & & 4,17 & 4,10 \\
\hline & Responsiveness & & & & \\
\hline 6 & $\begin{array}{l}\text { Ketanggapan petugas di dalam kereta api } \\
\text { LRT Jakarta terhadap keluhan penumpang }\end{array}$ & 397 & 404 & 3,97 & 4,04 \\
\hline 7 & $\begin{array}{l}\text { Kesiapan petugas di dalam kereta api LRT } \\
\text { Jakarta dalam menyampaikan informasi }\end{array}$ & 410 & 408 & 4,1 & 4,08 \\
\hline
\end{tabular}

Tabel 1. Perhitungan Rata-rata Terhadap Tingkat Kinerja Pelayanan dan Kepuasan Penumpang dalam Menggunakan LRT Jakarta 


\begin{tabular}{|c|c|c|c|c|c|}
\hline \multirow{2}{*}{ No } & \multirow{2}{*}{ Faktor Pelayanan } & \multicolumn{2}{|c|}{ Penilaian } & \multicolumn{2}{|c|}{ Rata-Rata } \\
\hline & & Kinerja & Kepuasan & $\mathrm{X}$ & $\mathrm{Y}$ \\
\hline & \multicolumn{3}{|c|}{ Rata-rata Responsiveness } & 4,04 & 4,06 \\
\hline & \multicolumn{5}{|l|}{ Assurance } \\
\hline 8 & $\begin{array}{l}\text { Kemampuan petugas LRT Jakarta dalam } \\
\text { melayani penumpang }\end{array}$ & 408 & 411 & 4,08 & 4,11 \\
\hline \multirow[t]{3}{*}{9} & $\begin{array}{l}\text { Penumpang merasakan keamanan dalam } \\
\text { melakukan perjalanan dengan LRT Jakarta }\end{array}$ & 416 & 408 & 4,16 & 4,08 \\
\hline & \multicolumn{3}{|l|}{ Rata-rata Assurance } & 4,12 & 4,10 \\
\hline & \multicolumn{5}{|l|}{ Empathy } \\
\hline 10 & $\begin{array}{l}\text { Kerapihan dan kebersihan di dalam kereta api } \\
\text { LRT Jakarta }\end{array}$ & 424 & 420 & 4,24 & 4,2 \\
\hline 11 & $\begin{array}{l}\text { Kepedulian petugas LRT Jakarta terhadap } \\
\text { penumpang }\end{array}$ & 409 & 409 & 4,09 & 4,09 \\
\hline \multirow[t]{3}{*}{12} & $\begin{array}{l}\text { Memprioritaskan penumpang berkebutuhan } \\
\text { khusus }\end{array}$ & 422 & 415 & 4,22 & 4,15 \\
\hline & Rata-rata Empathy & & & 4,18 & 4,15 \\
\hline & Rata-rata Total & & & 4,14 & 4,12 \\
\hline
\end{tabular}

Dari perhitungan rata-rata keseluruhan atribut/item pertanyaan kuisioner pada penilaian dalam menggunakan LRT Jakarta sebagai preferensi masyarakat, didapat hasil sebagai berikut:

1. Rata-rata kinerja pelayanan dalam menggunakan LRT Jakarta mencapai skor 4,14 maka dapat dikatakan bahwa kinerja pelayanan yang diberikan pada setiap item yang diteliti termasuk dalam kategori sangat baik.

2. Rata-rata kepuasan penumpang dalam menggunakan LRT Jakarta mencapai skor 4,12 maka dapat dikatakan bahwa kepuasan penumpang pada setiap item yang diteliti termasuk dalam kategori sangat puas.

Tabel 2. Perhitungan Rata-rata Terhadap Tingkat Kinerja Pelayanan dan Kepuasan Penumpang di Stasiun Velodrome

\begin{tabular}{|c|c|c|c|c|c|}
\hline \multirow{2}{*}{ No } & \multirow{2}{*}{ Faktor Pelayanan } & \multicolumn{2}{|c|}{ Penilaian } & \multicolumn{2}{|c|}{ Rata-Rata } \\
\hline & & Kinerja & Kepuasan & $X$ & $\mathrm{Y}$ \\
\hline & \multicolumn{5}{|l|}{ Tangibles } \\
\hline 13 & Akses stasiun LRT Velodrome & 409 & 404 & 4,09 & 4,04 \\
\hline 14 & $\begin{array}{l}\text { Tampilan eksterior dan interior Stasiun } \\
\text { Velodrome }\end{array}$ & 422 & 420 & 4,22 & 4,2 \\
\hline 15 & $\begin{array}{l}\text { Papan petunjuk angkutan lanjutan, } \\
\text { penempatan tanda sebelum pintu keluar } \\
\text { stasiun Kereta api yang mudah terlihat pada } \\
\text { Stasiun Velodrome }\end{array}$ & 408 & 415 & 4,08 & 4,15 \\
\hline 16 & $\begin{array}{l}\text { Fasilitas Stasiun Velodrome (toilet, mushola, } \\
\text { port charger, tempat duduk) }\end{array}$ & 410 & 408 & 4,1 & 4,08 \\
\hline & Rata-rata Tangibles & & & 4,12 & 4,12 \\
\hline
\end{tabular}




\begin{tabular}{|c|c|c|c|c|c|}
\hline \multirow{2}{*}{ No } & \multirow{2}{*}{ Faktor Pelayanan } & \multicolumn{2}{|c|}{ Penilaian } & \multicolumn{2}{|c|}{ Rata-Rata } \\
\hline & & Kinerja & Kepuasan & $\mathrm{X}$ & $\mathrm{Y}$ \\
\hline & Reliability & & & & \\
\hline 17 & $\begin{array}{l}\text { Keramahan pelayanan dari petugas stasiun } \\
\text { Velodrome }\end{array}$ & 408 & 411 & 4,08 & 4,11 \\
\hline \multirow[t]{3}{*}{18} & $\begin{array}{l}\text { Kesiapan petugas stasiun Velodrome dalam } \\
\text { membantu peumpang }\end{array}$ & 407 & 415 & 4,07 & 4,15 \\
\hline & Rata-rata Reliability & & & 4,08 & 4,13 \\
\hline & Responsiveness & & & & \\
\hline 19 & $\begin{array}{l}\text { Tanggap terhadap keluhan penumpang dan } \\
\text { menyelesaikan permasalahan yang terjadi }\end{array}$ & 402 & 407 & 4,02 & 4,07 \\
\hline \multirow[t]{3}{*}{20} & $\begin{array}{l}\text { Kesiapan petugas di stasiun Velodrome dalam } \\
\text { menyampaikan informasi }\end{array}$ & 411 & 403 & 4,11 & 4,03 \\
\hline & \multicolumn{3}{|l|}{ Rata-rata Responsiveness } & 4,07 & 4,05 \\
\hline & Assurance & & & & \\
\hline 21 & $\begin{array}{l}\text { Pengetahuan dan kemampuan petugas LRT } \\
\text { Jakarta di kawasan stasiun Velodrome }\end{array}$ & 406 & 411 & 4,06 & 4,11 \\
\hline 22 & $\begin{array}{l}\text { Terdapat papan informasi yang jelas di } \\
\text { stasiun Velodrome }\end{array}$ & 402 & 408 & 4,02 & 4,08 \\
\hline \multirow[t]{3}{*}{23} & $\begin{array}{l}\text { Kesesuaian harga tiket menuju stasiun } \\
\text { Velodrome dengan fasilitas yang didapat }\end{array}$ & 399 & 403 & 3,99 & 4,03 \\
\hline & Rata-rata Assurance & & & 4,02 & 4,07 \\
\hline & Empathy & & & & \\
\hline 24 & $\begin{array}{l}\text { Kepedulian petugas LRT Jakarta terhadap } \\
\text { penumpang di stasiun Velodrome }\end{array}$ & 404 & 404 & 4,04 & 4,04 \\
\hline 25 & $\begin{array}{l}\text { Kebersihan dan kerapian petugas dan stasiun } \\
\text { LRT Velodrome }\end{array}$ & 415 & 413 & 4,15 & 4,13 \\
\hline \multirow[t]{3}{*}{26} & Jaminan keamanan untuk penumpang & 400 & 403 & 4 & 4,03 \\
\hline & Rata-rata Empathy & & & 4,06 & 4,07 \\
\hline & Rata-rata Total & & & 4,07 & 4,09 \\
\hline
\end{tabular}

Dari perhitungan rata-rata keseluruhan atribut/item pertanyaan kuisioner pada penilaian stasiun Velodrome, didapat hasil sebagai berikut (lihat Tabel 2):

1. Rata-rata kinerja pelayanan pada stasiun Velodrome mencapai skor 4,07 maka dapat dikatakan bahwa kinerja pelayanan yang diberikan pada setiap item yang diteliti termasuk dalam kategori sangat baik.

2. Rata-rata kepuasan penumpang/pengguna LRT Jakarta pada stasiun Velodrome mencapai skor 4,09 maka dapat dikatakan bahwa kepuasan penumpang pada setiap item yang diteliti termasuk dalam kategori sangat puas. 


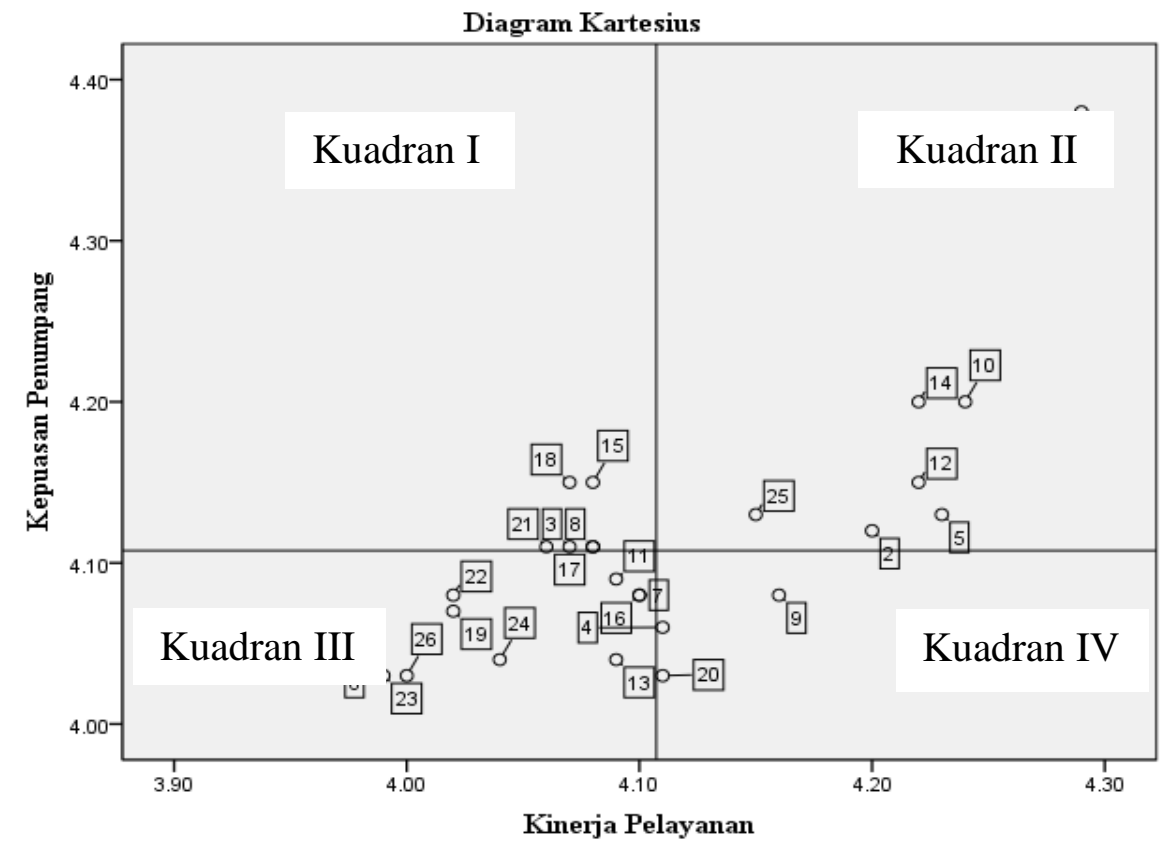

Gambar 1. Diagram Cartesius Importance Performance Analysis

Gambar 1 menunjukkan bahwa:

1. Pada kuadran I terdapat item-item preferensi pelayanan yang membutuhkan prioritas tinggi dalam penanganannya, yaitu item kuisioner bernomor $3,8,15,17$, $18,21$.

2. Pada kuadran II terdapat item-item preferensi pelayanan yang harus dipertahankan kinerjanya dalam kepentingan penumpang LRT Jakarta karena dianggap sudah baik, yaitu item kuisioner bernomor 1, 2, 5, 10, 12, 14, 25.

3. Pada kuadran III terdapat item-item preferensi pelayanan yang dianggap tidak terlalu penting dan kinerjanya juga rendah, cukup untuk dipertahankan, yaitu item kuisioner bernomor $6,7,11,13$, 16, 19, 22, 23, 24, 26.

4. Pada kuadran IV terdapat itemitem preferensi yang dianggap baik namun berlebihan sehingga menggunakan biaya/sumber daya yang tinggi, yaitu item kuisioner bernomor 4, 9, 20 .

\section{SIMPULAN}

Berdasarkan penelitian yang telah dilakukan pada moda transportasi LRT Jakarta, dapat disimpulkan bahwa aspek yang menjadi preferensi masyarakat dalam menggunakan LRT Jakarta yaitu berada pada kuadran II yaitu aspek yang memiliki kinerja baik terhadap kepuasan penumpang pengguna LRT Jakarta sehingga patut untuk dipertahankan. Sedangkan aspek yang butuh ditingkatkan untuk efisiensi dan efektivitas LRT Jakarta yaitu berada pada kuadran I yang membutuhkan prioritas tinggi dalam kinerjanya.

\section{DAFTAR PUSTAKA}

Gubernur Provinsi Daerah Khusus Ibukota Jakarta, 2007, 
Peraturan Gubernur Provinsi

Daerah Khusus Ibukota

Jakarta Nomor 103 Tahun

2007 tentang Pola Transportasi

Makro. Berita Daerah Provinsi

Daerah Ibukota Jakarta Tahun

2007 Nomor 105, Jakarta:

Sekretariat Daerah

Morlok, E.K., 1984, Pengantar Teknik dan Perencanaan Transportasi, Jakarta: Erlangga

Tamin, O.Z., 1997, Perencanaan dan Pemodelan Transportasi, Bandung: Penerbit ITB
Umar, H., 2011, Metode Penelitian untuk Skripsi dan Tesis Bisnis, Jakarta: Rajawali Pers

Widyaningsih, N., 2017, Evaluation of Passenger on Electrical Railway Services (Case Study Tanah Abang-Serpong), International Journal of Civil and Structural Engineering Research Vol. 5 Issue 1 pp 118124. 